\title{
EDUCATION IN LIFESTYLE MEDICINE
}

Camille A. Clarke, MD, John Frates, and Elizabeth Pegg Frates, MD

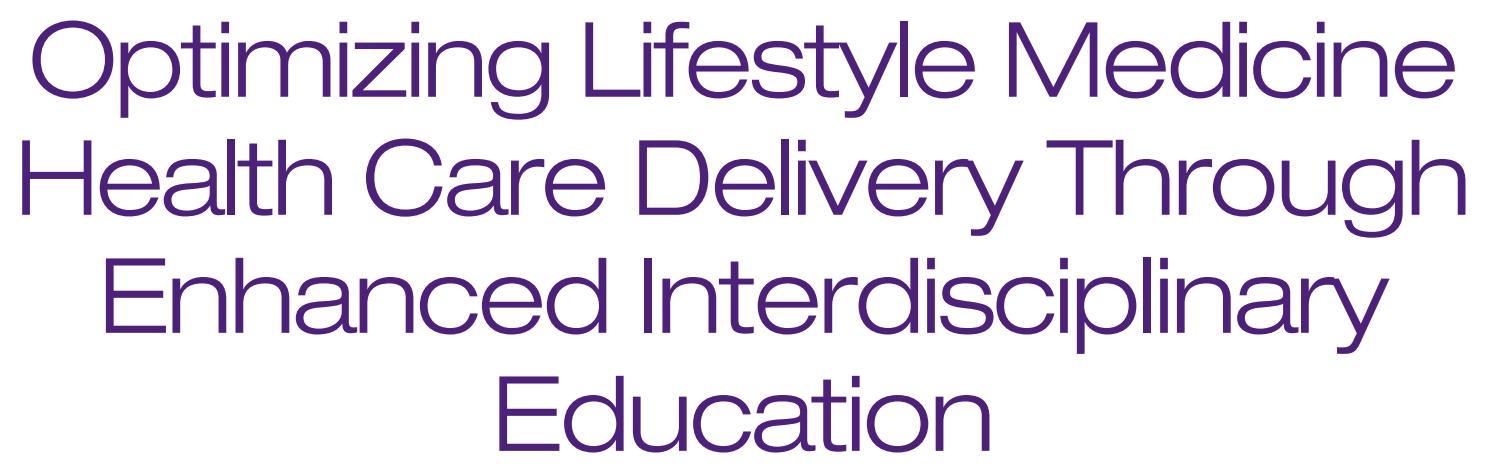

Abstract: While few may argue about the importance of healthy lifestyle choices on the effects of chronic health conditions, many would bighlight the challenge that its practical integration poses in daily clinical practice. The field of lifestyle medicine aims to assist individuals and communities to adopt and sustain healthy behaviors. It is a powerful yet often underutilized tool. This article illustrates the importance of joint multidisciplinary efforts in the effective practice of lifestyle medicine. Furthermore it stresses the importance of equipping healthcare providers with the tools and education necessary to deliver consistent, and high quality bolistic care.

Keywords: primary care; lifestyle medicine; shared decision making; health behavior; medical student; residency education

If don't have the training or the time." This is a sentence often uttered by health care practitioners regarding counseling on lifestyle modification. With the rising demand to reach quality measures and metrics, it is not surprising that physicians feel overwhelmed with recommendations to include lifestyle assessments and counseling into their habits is a significant challenge.

However, this challenge can be met with enhanced lifestyle medicine educational efforts and interdisciplinary teamwork.

Lifestyle medicine pillars, including a healthy eating pattern, routine exercise,

\section{ـ . . the job of caring for patients and providing guidance on how to adopt and sustain long-term healthy habits is a significant challenge.}

already demanding daily routines. ${ }^{1,2}$ Whether in inpatient or outpatient clinical settings, providers would likely admit that choices their patients make in everyday life significantly affect the trajectory of their disease courses and their health outcomes. With the lack of education in lifestyle medicine in medical schools and other health care professional schools, the job of caring for patients and providing guidance on how to adopt and sustain long-term healthy stress management, and supportive social connections, play key roles in health and wellness. For this reason, these healthy habits form fundamental principles in lifestyle medicine, which is defined as, "the systematic practice of assisting individuals and families to adopt and sustain behaviors that can improve health and quality of life." ${ }^{\prime 4}$ With the current shift in focus from a fee for service to quality measures and overall health care outcomes, emphasis is now being placed

DOI: 10.1177/1559827616661694. From Seventh Day Adventist Guam Clinic, Tamuning, Guam (CAC); Department of Medicine, Loma Linda University, Loma Linda, California (CAC); Roxbury Latin School, West Roxbury, Massachusetts (JF); Harvard Medical School, Boston, Massachusetts (EPF); Stroke Research and Recovery Institute, Spaulding Rehabilitation Hospital, Charlestown, Massachusetts (EPF); and Wellness Synergy, LLC, Wellesley, Massachusetts (EPF). Address correspondence to: Camille A. Clarke, MD, Seventh Day Adventist Guam Clinic, 388 Ypao Road, Tamuning, Guam 96913; e-mail: mme.cclarke@gmail.com. 
on postacute and chronic care management that influences long-term morbidity and mortality. While on the surface this requirement may demand more time from providers in order to learn the evidence-based information and techniques used in lifestyle medicine, in the end, the time and effort spent mastering this material will save time and can ultimately save lives. With adequate education and training in behavior change techniques, ${ }^{5}$ exercise prescription, ${ }^{6-8}$ nutrition basics, ${ }^{9}$ stress management, ${ }^{10,11}$ and the power of social connections, ${ }^{12}$ a lifestyle medicine practitioner can be effective and time efficient. With the support of a team trained in lifestyle medicine, lifestyle medicine practitioners can see more patients and provide high-quality care personalized to meet the needs of each patient. Some lifestyle medicine practitioners are currently practicing in teams and are enjoying the rewards of this interdisciplinary approach. ${ }^{13}$

Although physicians play a key role in addressing chronic disease and empowering patients to change their behaviors, many feel under equipped to give lifestyle recommendations due to their dearth of lifestyle medicine education and training. ${ }^{2}$ An article reporting on medical education revealed that more than $50 \%$ of medical students received no training in physical activity, according to a 2013 survey. ${ }^{14}$ With regard to nutrition, $71 \%$ of medical schools failed to provide the recommended 25 hours of nutrition education, according to a survey study performed during the 2012-2013 academic year. ${ }^{15}$ For stress management training, medical schools have emphasized helping medical students manage their own stress. ${ }^{16-18}$ Encouraging medical students to use stress reduction techniques is an important first step, and training them about how to counsel patients on stress management is a key next step. Current medical school education is deficient in these areas of lifestyle medicine specifically: physical activity, nutrition, and stress management. These gaps in the training and preparation required for physicians to practice lifestyle medicine

Table 1.

Survey Results From Trainees at the Annual Meeting for the American College of Lifestyle Medicine 2015.

\begin{tabular}{|l|l|}
\hline \% Trainees exposed to courses in exercise & 26 \\
\hline \% Trainees with nutrition block & 65 \\
\hline$\%$ Trainees instructed in lifestyle medicine behavioral counseling & 50 \\
\hline \% Trainees personally engaged in physical activity & 95 \\
\hline \% Trainees familiar with lifestyle medicine core competencies & 42 \\
\hline
\end{tabular}

must be filled by other means, such as continuing medical education courses. Most physicians, patients, and medical educators would admit that empowering patients to adopt and sustain healthy habits is critical to health on an individual level as well as a societal level. The responsibility to provide lifestyle medicine counseling, tools, and skills, does not have to belong to the physician alone. While it is essential that physicians take a leading role in this effort, it is also important that other professionals within health care are prepared to embrace this privilege and responsibility. Physicians, nurses, physician assistants, dentists, therapists, physical therapists,

occupational therapists, nutritionists, and exercise specialists need to work in teams along with other allied health professionals to effectively change the unhealthy culture that presides in the United States and worldwide. This is particularly relevant to patients who are sedentary, overweight, consuming fast food, experiencing daily stress, and feeling depleted. Chronic disease is a burden to them and the health care system alike.

The American College of Preventive Medicine (ACPM) expert panel, which developed 15 evidence-based competencies for practicing physicians, outlines the importance of an interdisciplinary team of care providers along with other elements, including collaborating with patients and families to develop action plans such as lifestyle prescriptions and practicing and promoting healthy behaviors. ${ }^{4}$
Furthermore, national organizations, such as the American College of Lifestyle Medicine (ACLM) actively address this through offerings to interdisciplinary health care providers. Its most recent national continuing medical education conference, in Nashville, Tennessee, saw attendance not only from interdisciplinary health care providers but also interdisciplinary trainees.

Approximately 750 health care providers interested in lifestyle medicine gathered for the annual meeting of the ACLM in Nashville in November 2015. At that meeting, the Professionals in Training Committee conducted a brief survey of trainees who attended the conference. The anonymous trainee survey explored the behaviors, knowledge, and needs of interdisciplinary trainees. Conference registration data demonstrated that there were 37 trainees attending the annual conference. The following fields of study were indicated by the trainees: 18 residents-MD/DOs, 9 medical students, 3 nursing students, 3 doctoral students, 1 master's student, 1 occupational therapy student, 1 physician assistant student, and 1 undergraduate student. Of the 37 trainees registered, 22 surveys were completed. Twenty-six percent reported they were exposed to courses in exercise; $65 \%$ reported having a nutrition block, and $50 \%$ received instruction on counseling about lifestyle medicine behaviors. Ninety-five percent reported that they personally engaged in physical activity. Only $42 \%$ of respondents were familiar with the lifestyle medicine core competencies (Table 1). 
The results in Table 1 demonstrate that exercise is the topic that receives the least attention in education and training programs. Interestingly, despite the lack of emphasis on exercise, $95 \%$ of trainees are experiencing the benefits of exercise and are personally prioritizing this particular aspect of the lifestyle medicine prescription. The majority of survey respondents were exposed to nutrition in their professional training schools, and half of the respondents were exposed to behavioral counseling. A striking finding from this survey is that less than half of the trainees attending the ACLM annual conference in 2015 were familiar with the lifestyle medicine core competencies. This statistic is a call for action to promote the lifestyle medicine core competencies.

Both the results from the survey and the variety of trainees in attendance of the annual meeting of the ACLM in 2015 demonstrate that students in medicine and other disciplines are seeking out opportunities to learn more about lifestyle medicine outside of their own professional training programs. Helping to satisfy this need, in 2016, the ACLM and the ACPM released a core competencies online curriculum which provides the opportunity for interested professionals in training as well as practicing providers to learn more about lifestyle medicine with an emphasis on the core competencies. ${ }^{19}$ Creating a variety of educational opportunities for learners to be exposed to the core competencies of lifestyle medicine is important for the future of health care delivery focused on treating the underlying causes of chronic disease. Curricular design targeting trainee education within varying disciplines is therefore needed and will prepare the next generation of providers for this present and rising need for lifestyle medicine core competencies. In fact, the team-based approach to healthful behavioral change in chronic disease management has proven its superiority and is steadily becoming standard of care inclusion in certain diseases. ${ }^{20}$

In medical schools, student-led efforts in lifestyle medicine education have been on the rise across the nation in the form of interest groups. Institutions such as Loma Linda University have had active student groups interested in lifestyle medicine since the 1990s. ${ }^{21}$ Harvard Medical School formalized the definition and creation of lifestyle medicine interest groups (LMIGs) in 2008. ${ }^{22}$ These LMIGs are faculty member-advised and student-led programs with different student presidents leading the advertising efforts and creating connections with fellow students to give the group a sense of cohesion each year. Harvard Medical School also designed a parallel curriculum for these LMIGs. ${ }^{22}$ The ACLM through the Professionals in Training Committee is promoting LMIGs. On the ACLM website under Professionals in Training, ${ }^{23}$ practitioners can find information about how to start an interest group. There are also tools to support the implementation of an interest group, such as standardized lecture PowerPoint presentations on topics including the following: Introduction to Lifestyle Medicine, Exercise Prescription, Nutrition Basics, and Behavior Change. All these PowerPoint presentations are available on the ACLM website on the Professionals in Training page. ${ }^{24}$ In addition, the ACLM supports the establishment of interest groups providing an award to students who are committed to starting an LMIG in their school. The award is open to medical students as well as other health care professionals in training programs. This is a deliberate attempt to encourage lifestyle medicine in all branches of medicine and in all health-related professionals in training. ${ }^{25}$

Medical students at Stanford University School of Medicine led the development of an interdisciplinary course,

"Introduction to Lifestyle Medicine." This course is offered to Stanford undergraduate, business, engineering, law, and medical students, which expands the target audience for lifestyle medicine. ${ }^{21}$ In September 2014, Harvard Extension School started offering an Introduction to Lifestyle Medicine Course through the Psychology Department. For the past 2 years, there have been 75 students in this course each year, attending from the United States and a variety of other countries, some of which are Canada, South Africa, Israel, China, Belgium, Sweden, and France. The students have diverse backgrounds, including undergraduates with a variety of majors (engineering, psychology, biology, and environmental studies) as well as a number of premedical students. There are a significant number of graduate students in psychology who enroll in this course, as it is offered through the Psychology Department. In addition, each year, there are practicing physicians who take the course. It is a 14-week course open to anyone interested in lifestyle medicine. The course can be completed in person on campus in Cambridge, Massachusetts, or remotely by computer from any location in the world. ${ }^{26}$ Efforts to educate undergraduate students with a variety of majors, graduate students in psychology, business, law, engineering, and other areas, as well as adults learners from across the globe with an interest in lifestyle medicine are growing in number and popularity.

Educating more than medical students in lifestyle medicine is essential for the widespread successful practice and delivery of lifestyle medicine. In 2007, an article was published calling for the inclusion of lifestyle medicine principles for US pharmacy students emphasizing the fact that pharmacists are highly accessible and can play an integral role in public health efforts for the prevention of chronic disease. ${ }^{27}$ As for specific areas in lifestyle medicine, developing nutrition curriculum is a topic of great interest to many health professionals in training in different parts of the world. For example, a recent article highlighted the need in West Africa for nutrition in medical school students, nursing students, nursing assistants, and midwifery students. ${ }^{28}$ Results from this study revealed that dedicated nutrition courses were reported in $100 \%$ of nursing assistant programs, $87 \%$ of midwifery programs, and $78 \%$ of nursing programs. For medical students, the nutrition 
material was embedded in other courses in $46 \%$ of medical school programs. Lifestyle medicine education has been encouraged and evaluated in different health professional training schools indicating an interest in and a need for these programs.

Schools of public health have appreciated the value of interdisciplinary teams in an effort to prepare their graduates for working on the difficult task of improving the health of the public. Lifestyle medicine, preventive medicine and public health share several areas of focus and overlap in a variety of ways. For several decades, University of Iowa College of Public Health, a leader in interprofessional education has used an interdisciplinary approach to education, including the schools of dentistry, medicine, nursing, pharmacy, and public health. Although they have been using this approach for decades, they report a recent increase in momentum and interest in their work. ${ }^{29}$ In 2008, the faculty at Brown School at Washington University in St. Louis used the power of different disciplines and crafted a Master of Public Health program that focused on using a transdisciplinary approach to problem solving. ${ }^{30}$ Since 2011, the University of California, Berkeley has offered a public health innovations course, which has been taken by students in 26 different graduate programs, including epidemiology, city planning, and mechanical engineering. ${ }^{31}$ In addition, The College of Public Health and Health Professions at the University of Florida reported that they have an explicit emphasis on collaboration between professions, colleges, institutes, and health centers across their campus. This collaboration is a critical component of their education because they believe that this is the best way to ensure that their 21st century learners enter the workforce prepared to tackle the difficult health problems perplexing the population at this time. ${ }^{32}$ The schools of public health are setting the example of interdisciplinary education, and lifestyle medicine programs can benefit from learning more about these crossdisciplinary efforts.
Making sure that lifestyle medicine principles are included in the education of multiple different health care disciplines is critical for consistent messaging about healthy living. Consistent messaging from the physician, nurse, psychologist, therapist, nutritionist, exercise specialists, pharmacist, and other health care providers involved with patient care are essential in order for patients to remember the message, to believe in the message, and to take action on the message. Furthermore, contradictory messages from health care professionals can dilute and even negate messages. For instance, if a primary care physician, knowledgeable about the health benefits of lifestyle change, counsels his or her cardiac patient on foods needed for improved health but the patient sees another provider shortly thereafter who informs that the patient can eat whatever he'd or she'd like since the cholesterol-lowering medication is working, the patient may be left bewildered. To complicate matters further, the patient may seek out an exercise expert who firmly believes in a highprotein diet with a heavy emphasis on red meat, which was discouraged by his or her primary care physician. This may drive the patient into a state of confusion and ultimate disbelief. Since there is so much confusion in the media and even in medicine around the optimal diet for health, ${ }^{9}$ it is important to have a united and consistent message that follows research and evidence-based principles integrated into the education and training of all health care training programs.

Given that the top causes of death in the United States are largely due to lifestyle-related chronic diseases, ${ }^{33}$ it is necessary to adopt strategies to incorporate lifestyle medicine in mainstream medical practice, and this begins with optimizing the medical training experience. While medical student education is vital, incorporating lifestyle medicine education in the training of health care professionals across disciplines is equally important. Lifestyle medicine conferences that offer continuing education credits to physicians as well as other health professionals are a good place to start, and some already exist. With such lifestyle medicine educational efforts, health care staff can work more cohesively and efficiently in teams, thereby saving time while improving patient outcomes.

\section{References}

1. Hebert E, Caughy M, Shuval K. Primary care providers' perceptions of physical activity counselling in a clinical setting: a systematic review. BrJ Sports Med. 2012;46:625-631

2. Barnes PM, Schoenborn CA. Trends in Adults Receiving a Recommendation for Exercise or Other Physical Activity From a Physician or Other Health Professional (NCHS Data Brief, No. 86). Hyattsville, MD: National Center for Health Statistics; 2012.

3. Barss P, Grivna M, Al-Maskari F, Kershaw G. Strengthening public health medicine training for medical students: development and evaluation of a lifestyle curriculum. Med Teach. 2008;30:e196-e218. doi:10.1080/01421590802334267.

4. Lianov L, Johnson M. Physician competencies for prescribing lifestyle medicine. JAMA. 2010;304:202-203.

5. Frates EP, Bonnet J. Collaboration and negotiation: the key to therapeutic lifestyle change [published online March 14, 2016]. Am J Lifestyle Med. doi:10.1177/1559827616638013.

6. Buford TW, Roberts MD, Church TS. Toward exercise as personalized medicine. Sports Med. 2013;43:157-165.

7. Frates EP, McBride Y, Bonnet J. It's fun: a practical algorithm for counseling on the exercise prescriptions: a method to mitigate the symptoms of depression, anxiety, and stress-related illness. Clin Exp Psychol. 2016;2:116. doi:10.4172/2471-2701.1000116.

8. Berra K, Rippe J, Manson JE. Making physical activity counseling a priority in clinical practice: the time for action is now. JAMA. 2015;314:2617-2618.

9. Katz DL, Meller S. Can we say what diet is best for health? Annu Rev Public Health 2014:35:83-103.

10. Mehta DH, Perez GK, Traeger L, et al. Building resiliency in a palliative care team: a pilot study. J Pain Symptom Manage. 2016:51:604-608.

11. Stahl JE, Dossett ML, LaJoie AS, et al. Relaxation response and resiliency training and its effect on healthcare resource utilization. PLoS One. 2015:10:e140212

12. Martino J, Pegg J, Frates EP. The connection prescription: using the power of social interactions and the deep 
desire for connectedness to empower health and wellness [published online October 7, 2015]. Am J Lifestyle Med. doi:10.1177/1559827615608788.

13. Kent K, Johnson JD, Simeon K, Frates EP. A case series: a team approach to behavior change [Published online March 21, 2016]. Am J Lifestyle Med. doi:10.1177/1559827616638288.

14. Cardinal BJ, Park EA, Kim M, Cardinal MK. If exercise is medicine, where is exercise in medicine? Review of U.S. medical education curricula for physical activity-related content. J Phys Act Health 2015;12:1336-1343

15. Adams KM, Butsch SW, Kohlmeier M. The state of nutrition education at US medical schools. J Biomed Educ. 2015;2015:357627. doi:10.1155/2015/357627.

16. de Vibe M, Solhaug I, Tyssen R, et al. Mindfulness training for stress management: a randomised controlled study of medical and psychology students. BMC Med Educ. 2013;13:107. doi:10.1186/1472-6920-13-107.

17. Kelly JA, Bradlyn AS, Dubbert PM, St Lawrence JS. Stress management training in medical school. J Med Educ. 1982;57:91-99.

18. Shapiro SL, Shapiro DE, Schwartz GE Stress management in medical education: a review of the literature. Acad Med. 2000;75:748-759.

19. American College of Preventive Medicine. Lifestyle medicine core competencies program. http://www.acpm. org/?page=lmprogram. Accessed July 5 , 2016

20. Milani RV, Lavie CJ. Health Care 2020: reengineering health care delivery to combat chronic disease. Am J Med. 2015;128:337-343

21. Clarke C, Edshteyn I, Zhu C. An emerging medical education competency: lifestyle medicine. SGIM Forum. 2015;38(2):1-2.

22. Pojednic R, Frates EP. A parallel curriculum in lifestyle medicine [published online December 6, 2015]. Clin Teach. doi:10.1111/tct.12475.

23. American College of Lifestyle Medicine. Professionals in training committed to treating the cause. http://www. lifestylemedicine.org/Student-Trainee. Accessed July 5, 2016.

24. American College of Lifestyle Medicine. The future of true "health" care is today's medical students embracing lifestyle medicine. http://www.lifestylemedicine.org/ INTEREST-GROUPS. Accessed July 5, 2016.

25. American College of Lifestyle Medicine. Donald Anderson Pegg Student Leadership Award. http://www.lifestylemedicine.org/ Donald-A.Pegg-Student-Leadership-Award. Accessed July 5, 2016.

26. Harvard Extension School. PSYC E-1037 Introduction to Lifestyle Medicine. https://www.extension.harvard.edu/ academics/courses/introductionlifestyle-medicine/14505. Accessed July 5,2016

27. Lenz TL, Monaghan MS, Hetterman EA. Therapeutic lifestyle strategies taught in
U.S. pharmacy schools. Prev Chronic Dis. 2007:4(4):A96.

28. Sodjinou R, Bosu WK, Fanou N, et al. Nutrition training in medical and other health professional schools in West Africa: the need to improve current approaches and enhance training effectiveness. Glob Health Action. 2014;7:24827. doi:10.3402/ gha.v7.24827.

29. Uden-Holman TM, Curry SJ, Benz L, Aquilino ML. Public health as a catalyst for interprofessional education on a health sciences campus. Am J Public Health. 2015;105(suppl 1):S104-S105.

30. Lawlor EF, Kreuter MW, Sebert-Kuhlmann AK, McBride TD. Methodological innovations in public health education transdisciplinary problem solving. Am J Public Health. 2015;105(suppl 1) S99-S103.

31. Sandhu JS, Hosang RN, Madsen KA. Solutions that stick: activating crossdisciplinary collaboration in a graduatelevel public health innovations course at the University of California, Berkeley. Am J Public Health. 2015;105(suppl 1): S73-S77.

32. Perri MG, Peoples-Sheps M, Blue A, Lednicky JA, Prins C. Public health education at the University of Florida: synergism and educational innovation. $A m$ J Public Health. 2015;105(suppl 1):S83-S87.

33. Mokdad AH, Marks JS, Stroup DF, Gerberding JL. Actual causes of death in the United States, 2000. JAMA. 2004;291:1238-1246. 